\title{
EFFECTS OF PARTIAL AND MICROBEAM IRRADIATION OF CELLS
}

A

SYMPOSIUM on partial and microbeam irradiation of cells was held in the University Department of Radiotherapeutics, Cambridge, on August 2 and 3, organized by a committee consisting of M. C. Bessis (Paris), R. H. Haynes (Chicago), J. S. Mitchell (Cambridge), C. L. Smith (chairman, Cambridge) and R. B. Uretz (Chicago). The aim of the symposium was to have an informal and intimate discussion on partial and microboam irradiation of cells and the techniques ancillary to such experiments. All participants were persons who are actively interested in or working in this rapidly growing field. Forty-five people attended, representing most of the European eountries, India and the United States. Each morning and afternoon was divided into two sessions in which a subject was introducod briefly by an invited speaker in the hope of provoking a frank, full and spontaneous discussion afterwards. In this it was extremely successful.

The symposium was opened by Prof. J. S. Mitchell, who reminded the delegates that it was just fifty years since the first papers were published in the field of cell micro-puncture (as it was called then) by Chahotin in 1912 .

The first morning was reserved for discussions about apparatus and techniques for producing microbeams of ultra-violet and ionizing radiations. In the afternoon, techniquos ancillary to partial cell irradiation were discussed; and the next day seven propared papers, some with films, were presentod.

'The first morning session was opened by M. C. Bessis with a ciné film showing the effects of localized monochromatic $(2460 \AA)$ ultra-violot radiation on hurnan leucocytes with a microbeam $l \mu$ in diameter. Out of this a discussion arose on the difficulties involved in measuring the energy flux over such a small area. R. B. Uretz described his technique of dofocusing the beam, allowing it to fall on a 'Willemite' screen, and measuring the phospholuminescence with a photocell. The difficulty of obtaining an absolute quantitative determination of the flux was stressed. Prof. J. S. Mitchell and R. H. Haynes pointed out that the important factor is the absorbed dose, and compared the measurement of energy flux and absorbed dose with the units röntgen and rad. M. C. Bessis proposed using a biological unit, and R. C. von Borstel (Oak Ridge) suggested that phago inactivation might prove a useful method for energy flux measurement as the phage are much smaller than the microspot and the inactivation produced could easily bo related to macro experiments for which the dose-inactivation curves are already well known or could easily be measured. Mitchell felt that nltra-violet photomicroscopy of the spot followed by microdensitometer measurements over the spot image should not be too difficult.

I. Nomarski (Paris) explained how it was possible to obtain an ultra-violet microbeam of $0.2 \mu$ diameter using the new Zeiss 'Ultrafluar' transmission achromat which has a numerical aperture of 1.25 and is corrected from $2400 \AA$ to $7000 \AA$. Uretz pointed out that scattering by subcellular constituents in most biological specimens made it impossible to produce an effectivo spot diameter less than abont 1 or $2 \mu$.
Bessis and Nomarski described a vory recently built system for producing an optical microbeam of wave-length $6930 \AA$ using a ruby laser and then showed a ciné film of some preliminary irradiations that have been porformed with this device on human erythrocytes; one flash produced complete hæmolysis instantanoously.

Uretz then described some experiments on chromosome 'paling' using a polarized microboam of ultraviolet. No observable difference could be seen between the effects produced by two beams polarized in planes at right angles to each other.

The second morning session was opened by L. D. England (Toxas Nuclear Corporation), who described a technique for single proton irradiation of solected areas of single living cells. The protons of $16 \mathrm{MeV}$ energy aro produced by the nuclear reaction ${ }^{8} \mathrm{He}$ (d.p.) ${ }^{4} \mathrm{He}$. The discussion then centred around means of producing microbeams of ionizing radiation. D. Harder (Würzburg) talked about an $\alpha$-particle microbenm which he had constructed, and Smith describer how $5 \mu$ holes in platinum could bo squeezed and, by plastic deformation, reduced to a diameter of $2 \mu$. Haynos thon discussed a method of producing holes down to $1 \cdot 5 \mu$ in diameter by controlled punching of a thin metal foil with a hard-steel needle and stressed that the diameter of the beam must be measured by nuclear plate techniques and not just taken as the diameter of the hole measured optically. He followed this by describing the localization and calibration techniques associated with his own $x$-particle microbeam.

The afternoon session of the first day, on ancillary techniques, was oponed by 'T. R. Munro (Cambridge) describing his tissue culture technique whereby single S3 HeLa cells could be followed for 7-8 days until they formed clonos containing up to 100 or more cells. By this means he hopes to observe long-term effects of partial cell irradiation. Both Uretz and $\mathrm{H}$. Glubrecht (Hanover) then commented on methods of partial cell irradiation using selective radioactive procursors containing hydrogen-3, sulphur-35 and phosphorus-32. Glubrecht stressed the importance of the effect of transmutations, particularly of incorporated phosphorus-32.

J. G. Cruickshank (Cambridge) opened a discussion on the uses of the fluorescent antibody tochnique and described a proposed experiment involving HeLa cells infected either with Newcastle disease virus or influenza virus. Tho effect of ultra-violet 'enucleolation' on synthesis of RNA could then be observed either with radioactive precursors (for example, tritiated uridine) or acridine orango. Uretz discussed experiments using a 'phosphoroscopo' in which an induced fluorescence with a lifetime $>10^{-4}$ sec could be observod.

L. Trapp (Zeiss, Oberkochon) described the new Zeiss Caspersson type (ultra-violet and visible) scanning microspectrophotometer with automatic recording.

On the second day, the following papers wero presented: P. S. Amenta (Philadelphia), "Effects of Ultra-violot Mierobeam Irradiation on the Eosino- 
phils of Triturus viridescens"; J. G. Carlson (Knoxville), M. E. Gaulden and J. Jagger (Oak Ridge), "Mitotic Effect of Monochromatic Irradiation of the Nucleolus"; R. Rhines (Chicago), "Some Effects of Irradiating Small Portions of Neurites in Cultures of Nervous Tissue with the Uretz Ultra-violet Microbeam"; J. Jagger and D. M. Prescott (Oak Ridge), "Ultra-violet Microbeam Irradiation of Nucleus and Cytoplasm of Amoeba proteus"; H. Ulrich (Zurich), "Partial Cell X-ray Experiments on Drosophila melanogaster Eggs: Sensitivity to Killing and Production of Mutations"; M. I. Davis Clegg (Oxford), "Some Preliminary Results of Electron Microscope Studies of Cells Irradiated with a Microbeam of
$\alpha$-Particles"; A. Gibor and S. Granick (New York), "Cytoplasmic Inheritance of Plastids".

The meeting was concluded with an expression of thanks to Euratom for financial support. There was a general feeling among the participants that small meetings of specialists in a given field can stimulate discussion and research probably better than large conferences. At the invitation of Prof. M. C. Bessis it was agreed to hold another informal meeting in Paris in two years time.

The participants then made a tour of the new laboratory, during which they saw the various pieces of microbeam equipment in the laboratory and discussed the work in progress. $\quad$ C. L. Surte

\title{
PRODUCTION OF HYPERSENSITIVE CONDENSATION NUCLEI
}

\author{
By $D_{R}$. G. R. EVANS and A. A. WATSON \\ Department of Natural Philosophy, University of Edinburgh
}

$\mathrm{D}$ URING the course of experiments originally undertaken to ascertain the nature and cause of background fog in a Wilson cloud chamber some results have been obtained which may be of interest, to workers in other fields. This fog, which spoils track photography, can be avoided by interposing a number of slow expansions between the fast expansions used for photography: the more dense the fog background, the greater is the number of slow expansions necessary to clean the chamber. The fact that these fog nuclei form drops during slow expansions when the degree of supersaturation is low indicates that they are efficient condensation nuclei.

In normal operation of a cloud chamber, an electric field is maintained across the chamber for the purpose of sweeping away ions formed between expansions. It was discovered that when this field is maintained continuously it becomes more difficult to clean the chamber of fog nuclei, suggesting that an electric field is somehow involved in their formation. Further investigation showed how important it is to remove all traces of fluff from the electrodes if the chamber is to be cleared effectively with the electric field continuously applied.

In order to examine this problem in more detail, a thin strand of cotton was attached to the end of a thick copper electrode and placed at the centre of a cloud chamber, of diameter $20 \mathrm{~cm}$ and axial length $20 \mathrm{~cm}$, containing nitrogen at a pressure of 30 atmospheres and saturated with water vapour at $20^{\circ} \mathrm{C}$. The electrode was connected to a d.c. voltage which was variable from 0 to $1.2 \mathrm{kV}$. Adiabatic expansions were made using a range of expansion ratios of 1.01-1.07, the corresponding fall in temperature being from $1^{\circ}$ to $8^{\circ} \mathrm{C}$. The chamber was first cleaned by slow expansions (in which state no drops are observed even with an expansion ratio of $1 \cdot 12$, provided that in the meantime no electric field has been applied). Thereafter the electric field was applied either during or after an expansion. In such expansions, several jets of drops were seen to issue forth from the tip and side of the cotton strand.

At first, the jet is hollow and shaped like an eartrumpet, the drops moving away from the region of the cotton with a speed of approximately $2 \mathrm{~cm} / \mathrm{sec}$ (Fig. 1). Eventually, the drops are dispersed throughout the chamber, the fog becoming too dense to determine for how long the process continues. It is not nocessary that the field should be applied during

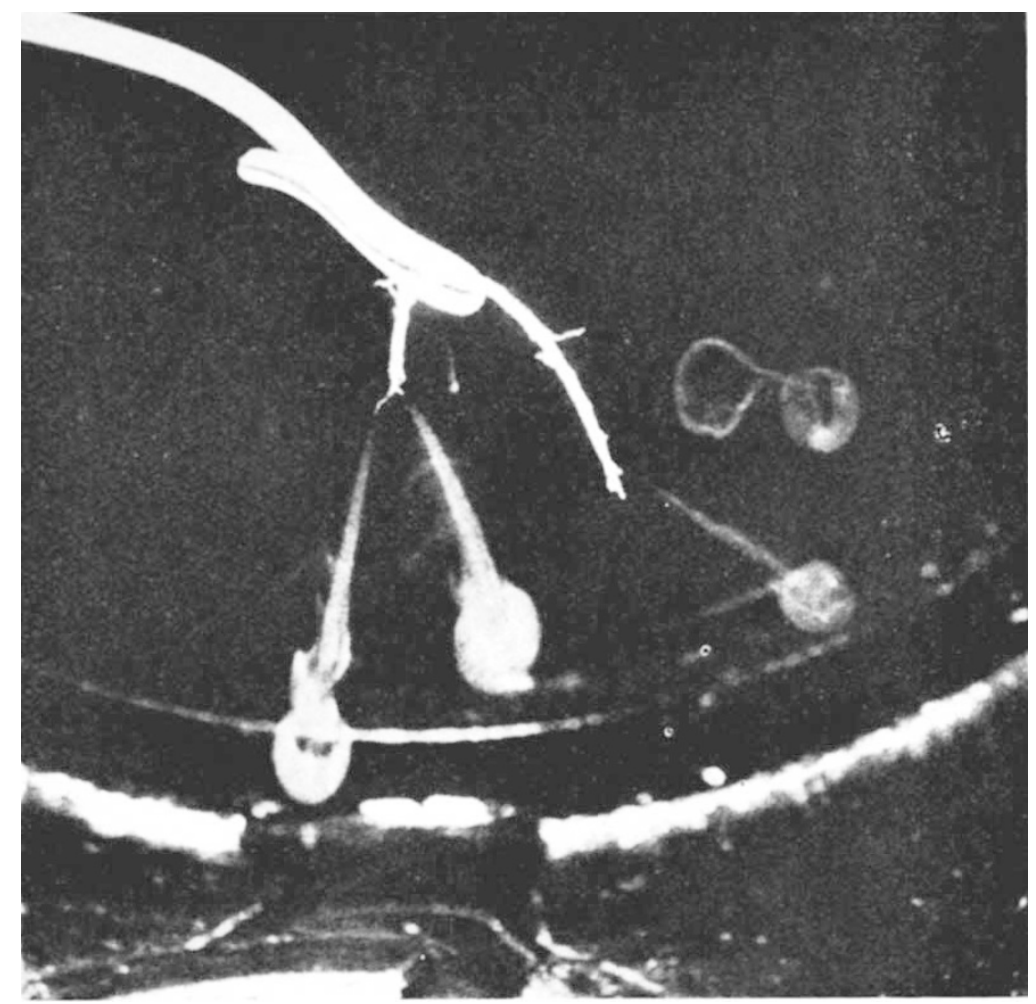

Fig. 1. Jets produced in nitrogen at 30 atms., saturated with water vapour. Photograph taken 2 sec after an expansion of 1.02 . Potential on electrode $-400 \mathrm{~V}$ 